\title{
Mobile-Learning Realization and its Application in Academia
}

\author{
Khalid A. Fakeeh, PhD \\ FCIT, \\ King Abdullaziz University, \\ Jeddah, Saudi Arabia
}

\begin{abstract}
The advancement of handheld portable gadgets or devices and wireless innovation has brought about radical changes in the social and economic ways of life of contemporary or modern individuals. Today, numerous technological gadgets/devices are delivered in versatile form and individuals have ended up usual to them. These devices are reshaping client's everyday lives in diverse ways. Be that as it may, the improvement of computerized innovations has so far been restricted to social correspondence or communication and few individuals have viewed mobile learning as a core pedagogical or educational accomplishment or activity in higher institutions of learning. Mobile learning is grabbing its predominance as it is recognized to be an intense arrangement of passing on lesson and securing knowledge as its standard qualities are at whatever time and wherever. It can be utilized from various perspectives in the education milieu or domain. We have outlined the convincing aspects in this paper that contribute for mobile learning utilization and also issues and challenges in grasping mobile learning.
\end{abstract}

\section{Keywords}

E-learning, Mobile Learning, Higher Education

\section{INTRODUCTION}

Extended change in technology consolidated with an extent of prerequisites and cravings from an extent of accomplices have made it essential for academia to dependably update their frameworks and courses of action in teaching and learning as a way to deal with stay powerful and centered. The penetration of IT has made learners to end up logically PC educated. The extended use of these PDAs like iPad, phones, handphones, tablets and PDAs is a general miracle [1]. Students bring these advancement wherever, at whatever time for their consistently endeavors. Teachers should look upon this wonder as an open entryway however without a doubt it is a test as well. The thought of "at whatever time" and "wherever" of mobile learning should be utilized as a part of overhauling the pedagogical or educational activities in passing on lessons. As of late there has been impressive enthusiasm for the utilization of mobile technology in training/education, despite the fact that the innovation is as yet advancing. The inquiry is the reason the abrupt curiosity, particularly in nations that have extensive scale realization of mobile technology in academia. A few nations have attempted activities to execute the utilization of tablet PCs and PDAs so that their residents can utilize the innovation to learn and to interface with the world. In the Gulf area, the United Arab Emirates (UAE) is playing a main part in actualizing the utilization of high-end tablets for students to learn [61][62]. The State of Qatar is playing an initiative part in creating and scrutinizing portable learning in the work environment. A present venture subsidized by the Qatar Foundation is researching the utilization of mobile learning out how to prepare representatives on work environment English in the oil and gas industry [63]. Nations somewhere else with comparative activities incorporate South Korea, Brazil, Thailand, and India. A few nations are digitizing so as to go above and beyond learning assets, for example, reading material, manuals, and so forth for access on portable advancements. For samples, South Korea is wanting to digitize the entire K-12 educational programs for tablet PCs by 2015 [64]: students will bring a tablet with the electronic materials to class as opposed to substantial course books and manuals. These nations and different nations around the globe are understanding that the utilization of mobile technology is an approach to teach all citizens and a few nations understand that having residents connected with the web or internet utilizing rising advances, for example, portable innovation, is a financial point of interest. In any case, more research is expected to decide how mobile technology sways academia or education with the goal that mobile learning activities can take after appropriate practice in their realization.

\section{MOBILE LEARNING}

Following are some figures to have a clear picture of MLearning: 


\section{MOBile LEARNing MADE EAsy}

\section{LEARNiNG APPS}

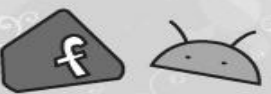

Go gle

:s: BlackBerry
TEACHING TOOLS

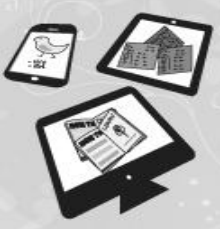

CREATE

SHARE

CONNECT

MEASURE
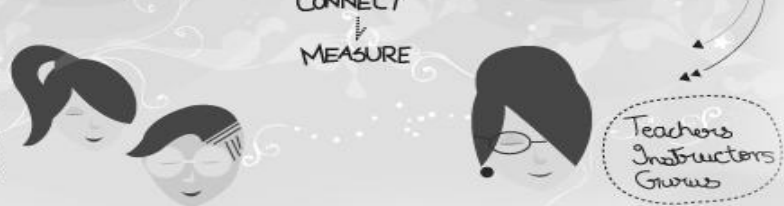

\section{Advantages}

There's something for everyone with Mobl21!

Learners study on-the-go

\& collaborate, educators

create content, connect \&

measure results.

(a)

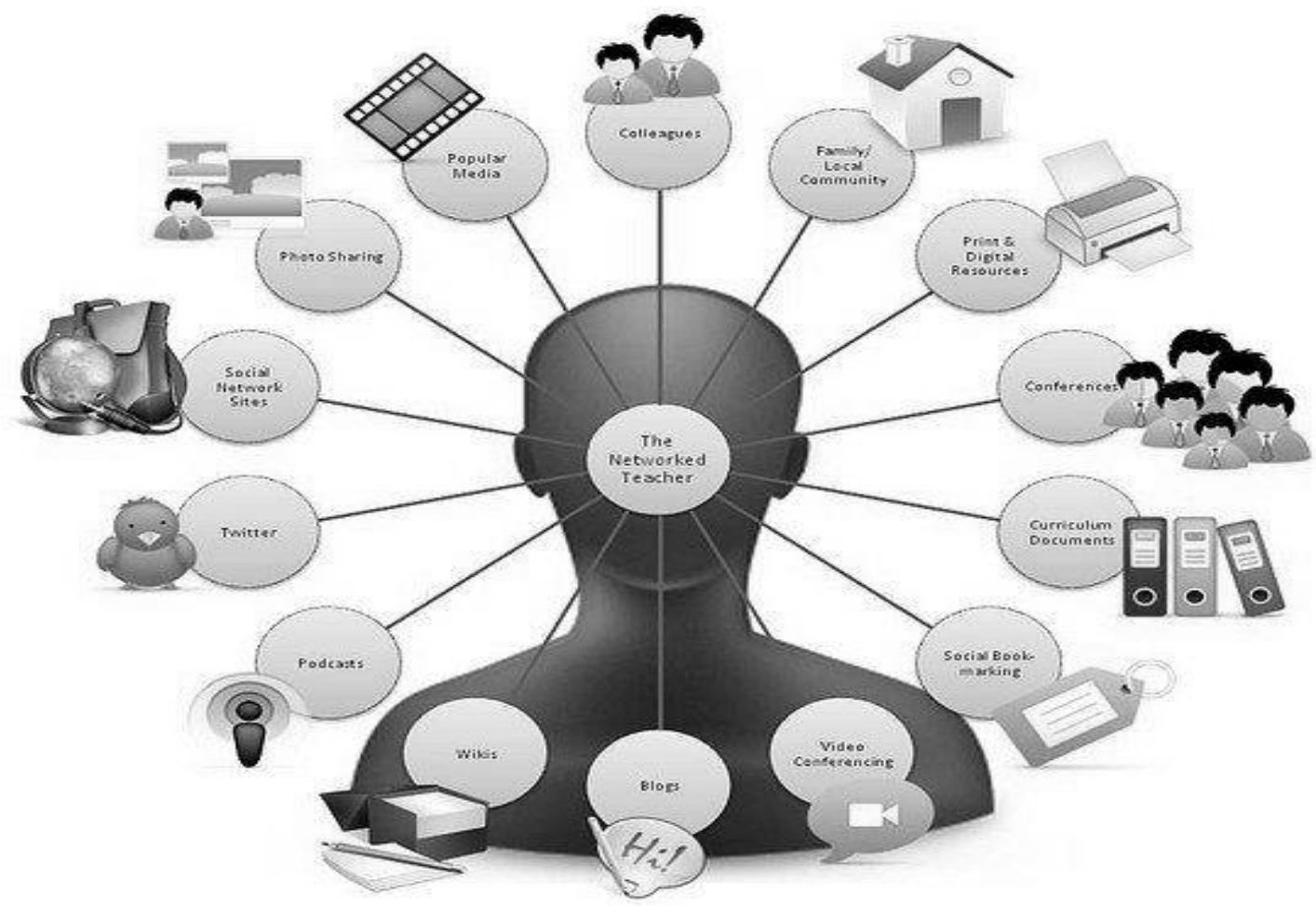

(b)

Fig 1 (a, b): Mobile Learning Concept 


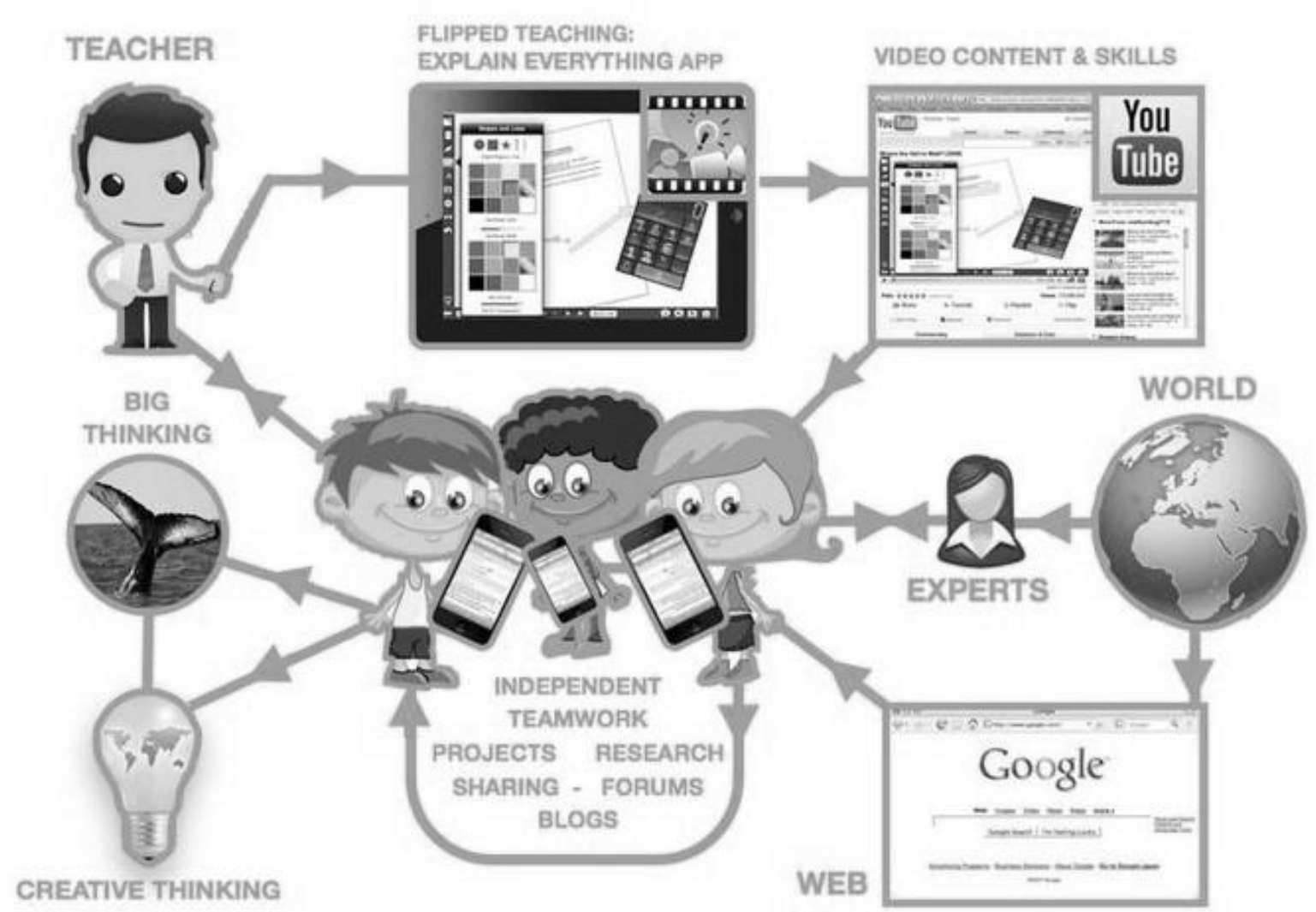

(a)

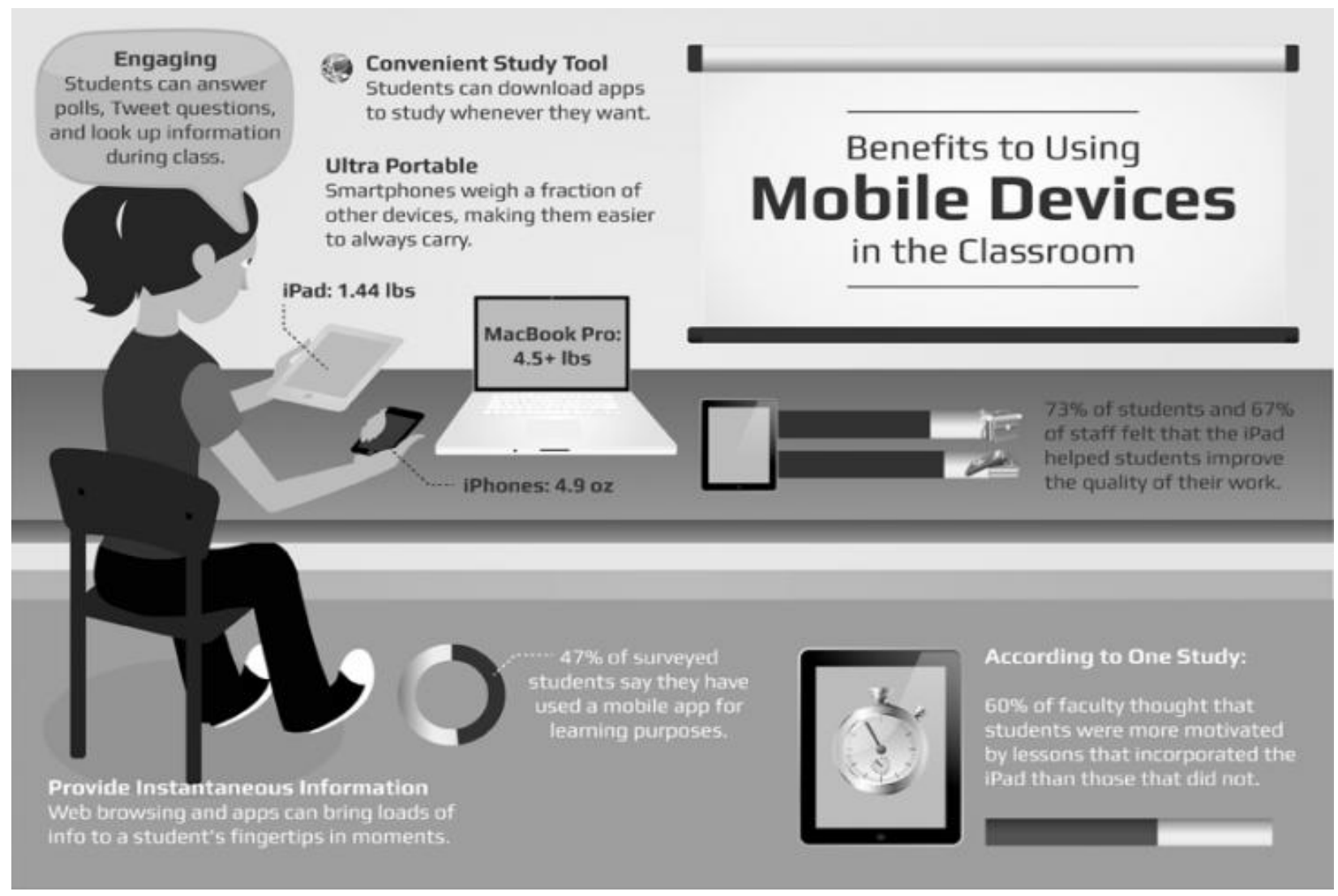

(b) 


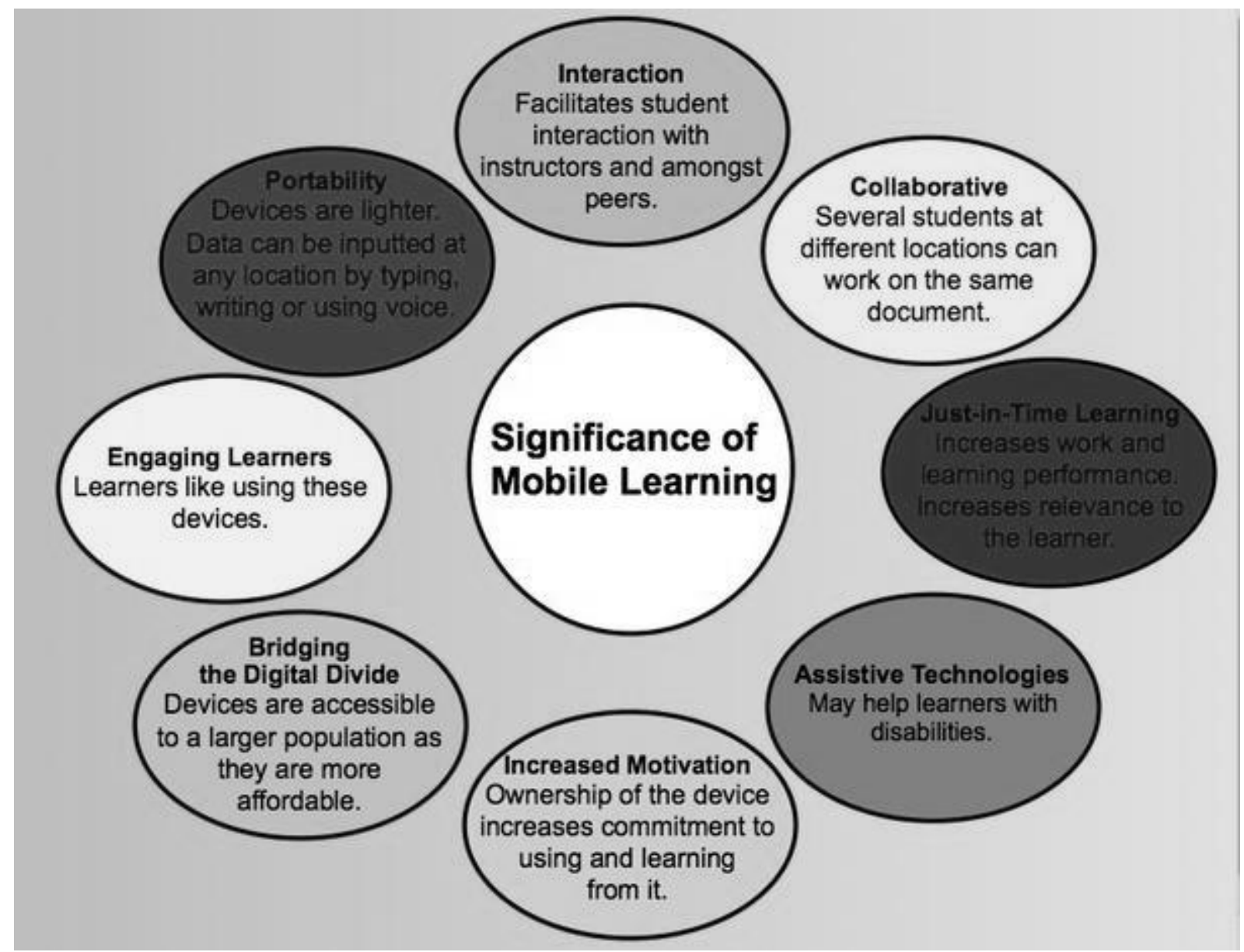

Fig 2 (a, b, c): Mobile Learning use in Classroom and its Significance

\section{MOBILE LEARNING THEORY, APPLICATION \& INFLUENCING ASPECTS}

M-learning becomes known as a result of individual-toindividual correspondence via mobile phones [2]. Mobile Technology is a main system to support M-learning. These little, adaptable and self-administering devices have made a couple of experts described M-learning considering the physical estimations of the devices [3][4]. A substitute thought to portray M-learning spotlights on the versatility of the learners [5]. This was further elucidated and described as the sort of finding that could be formal within the classroom, or easygoing outside the classroom, and the learner has the preference to pick when and what to acknowledge [6]. In summary, the above thoughts and contemplations in portraying M-learning recommend that learner, mobility, adjusting in every practical sense wherever and at whatever point, through phones, are the key characteristics of Mlearning. Study on the teaching and learning through Mlearning has transformed into a rapidly propelling domain [7][8]. The region of M-learning consolidates the novel teaching and learning procedures and the wide arrangement of mobile applications. To date, various researchers and specialists have investigated the delivery, technique and credibility of PDA or mobile usage in academia, particular reinforce, the building of IT establishment and diverse resources. In view of the fact that the infiltrate of M-learning, there have been diverse studies coordinated. To give a few samples, there were studies coordinated outside of the school or learning establishment compound [9] [10] , a haven [11], a wetland [12], and the sea [13], within the learning foundation compound like watching plants [14] and taking a gander at the impact of passing on competency based assessment through PDA's. (PDA) [15] notwithstanding fundamentally more others that have been carried out. So far the studies on Mlearning have shown essentially positive results. Eventually, there are some who addresses the strength and reasonability of M-learning particularly as the vitality of investigating devices is seen as a transient response. Different researchers are of the supposition that mobile technology should be seen as the increase as opposed to supplanting the present teaching and learning tools [16], [16] [17]. Additionally, not all learning substance or activities are suitable with the mobile devices [18].

\subsection{Influencing/Convincing Aspects:}

There are broad amounts of aspects that energize learners and teachers to bring into play mobile applications. To successfully get M-learning, thought must be given to these convincing aspects. The experts analyzed and coordinated the aspects by looking at the writing in which the PDAs were utilized as the teaching and learning gadgets. Thusly, the convincing aspects were gathered into three key classes with a couple subcategories. The three guideline characterizations are the parts of the devices, customer's cravings and academic purpose of inclination. 


\subsubsection{Devices traits:}

These were further subcategorized to be particular: usability, technical and functional [19].

\section{A. Comfortability or Usability:}

From the comfort edge, M-learning gadgets or devices are minimal, light, and portable or convenient [20][21]. These traits make the learners feel quiet as learning is no more restrictive to the classroom with monstrous rucksacks containing stacks of books and other learning materials. Such open door makes the system of knowledge transmission gets the opportunity to be versatile and can be executed at whatever time and wherever.

\section{B. Serviceable or Functional:}

For all intents and purposes, the devices can give minute and unconstrained information [21] [22] [23]. There are times when learners really need to get certain information speedy. Case in point, energetic reactions to specific request as definitions, formula and examination. The devices will push the learners to quickly interest such information. Intelligibility or permanence is another efficient trait. M-learning is a learning model that permits the learners to get learning materials wherever and at whatever point. To have the ability to continue with the learning without the necessities of time and territory is an imperative part that impacts how learners may be provoked to make use of their mobile applications [24]. Learners' access to information and learning material does not as per usual stop as a consequence of their zone. As a general rule learners can get to and team up at distinctive spots and in an assortment of circumstances.

\subsubsection{Prospect or Expectation of Customer's: \\ A. Proprietorship:}

[25] concentrated on various productive M-learning endeavors in the methods of the mLearn social occasions from 20022005, and perceived five essential accomplishment highlights. One of five fundamental segments indicated in the study is proprietorship. From the point of view, learners will end up being more motivational, more dynamic in correspondence and learn limitlessly enhanced when they either own the learning gadget or see it as if they have it [26][27].

\section{B. Confidentiality:}

In differentiating mobile phones and other computing gadgets, clearly, the past offers the learners confidentiality assurance. Mobile applications give the private virtual world to the learners that make them feel secured and impelled. Having confidentiality will give various inspirations to learners to team up with the devices. The learners can get to information and download autonomously from diverse learners [28][29][30].

\section{Flexible or Versatile learning:}

High mobility of learners nowadays constructs versatile learning indispensable. M-learning unlocks further open entryways for learning to take place not considering of place and time. The learners have the adaptability to exist in unmistakable zone than the educators, to learn at their own pace and time granted that they have the hardware and network infrastructure or framework base [34].

\section{Self-Regulated learning:}

Researchers extend the enormity of allowing learners to practice more power or control over their own specific learning. The learners will presumably deal with learning experiences in case they are asked to have more dynamic influence in their learning [31][32]. M-learning opens up the open entryway for the learners to be at the point of convergence of the learning strategy, expect a dynamic part starting from choosing their target until the appraisal phase [33]. When they are viably joined with the task, they will likely make learning approaches that will help their learning progression, thusly, add to their motivation. Not under any condition like other digital media, a mobile device can be carried all the time and bestows its customer's exceptional measure of control over how and when to get to their mobile devices or PDAs.

\section{E. Profound established learning (Life-Long):}

In light of the current financial, social change, and move to data/knowledge based society, enduring learning has transformed into an essential national inspiration in numerous countries. Flexible learning is seen as one instrument/tool that can seem dependable or life-long learning. [35] and a practically identical assignment grasped at the Tampere University of Technology (Finland) [36] have researched lifelong learning through mobile phones or PDA's.

\section{F. Excitement or Fun:}

Entertainments are considered as a basic segment affecting the usage of mobile applications. [37] argue that digital games are not just for the purpose of amusement, or for vital study of school subjects, they can in like manner be used solely to learn. The learners understand each one of the aptitudes that are embedded in each level in the game, get the chance to be secured and motivated and don't comprehend that they are honestly learning. This is the spot Prensky battles that as learners play the game, they feel a surge and engagement they don't frequently feel while learning in school. Consequently, these automated entertainments have transformed into the replacement to a universe of acknowledging where everything learners learn is out-dated, and essentially debilitating.

\subsection{Educational or Academic benefit: A. Group learning:}

Social enclosure is the best approach to group or collaborative/mutual/group learning. The learners coordinate towards one ordinary goal. As an aftereffect of their accessibility, mobile phones reinforce joining and consider more open entryways for venture, and consequently, learning ends up being more victorious. Various researchers or scientists advocate the usage of mobile technology that enhances learners joining in the learning method [38][32][39][40][41][42].

\section{B. Interactive learning:}

Adaptable headways in like manner reinforce natural or interactive learning environment [45][46]. The mobile phones limit as the interactive pros that allow unreliable levels of instinct and engagement with the development, in this manner enable the method of coming to know happens which shows that the learning is happening.

\section{Blended or Unified learning:}

It merges classroom instructions with M-learning can overhaul and open up the face to face and online schedules [42][43]. The learners can do their assignments and endeavors via mobile phones after a class session with their teacher.

\section{Empirical or Experiential Learning:}

The convenience of the devices mull over acknowledging which is not constrained restricted to the informative circumstances. The tools build up the link amidst school and other common activities [47]. This bestows the thought that education can go past the classroom setting and things that are 
critical to the learning itself can be brought into the classroom and the differing parts of the visit can be improved for learning purposes. [48][49].

\section{E. Issue-based learning:}

A wander or project in Norway [50] is one case that Mlearning support Problem-Based Learning. Smart phones and PDAs were brought into play for assessment in medical education of understudies/students from the School of Medicine at University of Oslo. In this learning, the learners adequately discover and work with content that they choose to be vital to deal with the issue given by the instructor.

\section{M-LEARNING APPLICATIONS CONCERNS AND DEFIES}

Different concerns and defies may point of fact appear in grasping M-learning practice. Most concerns and defies are all that greatly related to the mobile phone aspects or segments and a couple as to customer's wishes, However, in educational problems or concerns, especially the context-constrained and educational specific which is insinuating how stable the applications are similarly as their educational and learning content problems [51]. The gap here is not because of there is no issue exists concerning the teaching and learning through M-Learning yet rather in light of the way that there is a nonattendance of all around studies on these edges. Some issues and defies are the following:

\subsection{PDA's or Mobile Phones Aspects: \\ A. Comfort or Usability Aspect:}

The elementary concern or problem of usability is the undersized screen size. The present mobile devices are builtup with the center of attention to permit customers to enter and get to sorted out data like lists, contacts, dates, cash related information, and updates, to send and get messages, to view reports and pictures, or to get to the web [52]. A study on using a PDA for learning purposes revealed inconveniences in examining in light of the pitiable screen display [53]. The little, touch fragile screens of phones can stance issues in investigating the screen with fingers and learners may accidently pick a limit or function, for instance, deleting a record. Additionally, the ergonomic and cognitive problem [52] which is related to the starts of differences between using PCs and mobile phones, print material and electronic minimal size outlines of sweeping compositions. Ergonomic problems take in the anxiety of eradicating diary sections from the device. Both ergonomic and cognitive problems could position defies for customers as they bring into play mobile phones and they may require a learning period to get accustomed to the contraptions or devices. Thirdly is the nonattendance of relentless layout arrangement. There is no far reaching stage exist between phones in light of the fact that each maker adds to their own specific unprecedented customer interface [52]. The problems of compatibility ought to be resolved in light of the way that we can't foresee that the learners will move among the devices to find the most suitable one for the school wanders. Also, there will be concerns in synchronizing the understudies' assignments via mobile phones and later in looking over them. M-learning must be restricted to spaces where likeness or compatibility concerns or matters won't surface.

\section{B. Technological or Technical Aspect:}

As far this aspect or feature is concern so there are a couple of issues in regards to technical aspect. At first is the accessibility issue that insinuates the issues of system in particular places, and problems of intuitive blend between the hardware and software of the device [54]. A study exhibited that the respondents had issue with PDAs in perspective of moderate transmission [55]. They moreover focused on that the electronic book material that was made accessable was not important, nor was the usage of advising organizations for group learning. Likewise, they also experienced issues working transversely over particular applications. Likewise, the life of the batteries in which downloading informative applications and diversions uses up batteries much speedier especially when bringing into play free applications [56]. Studies found that the energies of batteries continue being drained even after the downloading of information has wrapped up. The problem of battery life is so far something of a test while uniting the devices into the instructive modules as the learners may not be adequately prepared about this matter; continue playing entertainment to the highest noteworthy, disregard to shut down and in this manner, when the time searches making sense of how to happen the batteries decrease. Problem of accessibility is another that teachers must be all that much mindful of. Different contraptions/devices may have near or particular accessibility highlights. Today, it is a present for the remarkable needs learners as there are imaginative works in accessibility [57]. Teachers need to ensure every understudy or student will benefit by the present contraptions/devices or else ascend to decisions for those not ready to move the advances should be given. Besides that, there is a security concern, wellbeing, burglary and setback. Computerized wrongdoings or cyber crimes are transforming into a danger as headways flourish. Individual and association data are regularly secured in the mobile devices for accommodation when the need develops. Being portable and minute nature makes the contraption tolerably easy to lose or take. The data can be stolen despite when you use the contraption [58]. Occasions of stalking, wholesale misrepresentation and cyberbullying are going on and there is no standard system for guaranteeing the customers. Customers are simply educated with respect to the perils and given tips on the most ideal approach to minimize. How competent, good and safe the learners bring into play the contraption or device is moreover another topic that ought to be well thought-out. Another most important concern is the storage problem. Another weakness of mobile phones is the inability to hold a huge amount of data which has realized various people to change into cloud computing. Of course, this open cloud services have also exhibited not safe. Might 2012, IBM uncovered a bring-your-own-device (BYOD) system and banned the utilization of Dropbox as a result of software engineers [59]. Taking after this, teachers need to strategize their lessons fighting fit in particular when overseeing compelled storage aptitudes.

\subsection{Customer Prospects or Expectations: A. Expenditures:}

To add in mobile phones, MP3 players or other PDAs under the control of every learner would be pricey even though PDAs cost lesser than PCs. It will take much financing and surrenders to make M-learning in a more accessible option for a few classrooms. In fact, to adequately turn up mobile technology exercises, a significant measure of expenses must be rendered on stuff far past basically the cost of the devices. The best expenses begin from resources required like the cost of making and passing on M-learning systems [60].

B. Obstruction or Impediment:

Instructors need to get themselves clear with the school's game plan concerning web systems administration like social 
media, and others before they truly think about their teaching and learning frameworks that make use of or bring into play such media. This is to keep up a vital separation from disappointment on both sides if such sites is been obstructed by schools.

\section{Obsolescence (obsolete/Out-of-Date):}

As far as progression is concern so no one can make certain in the matter of how more development is going to progress later on. One thing that it can be assured is the change makes the more novel devices or contraptions can perform more, have superior and upgraded limits and assessed sensibly or economically. The grown-up version can be functionally or technically obsolete (What is, 2006). Thusly, the lessons that the educators or instructors come up at present on modernized training for case, may wrap up pointless as innovative alternatives might just show up weeks after they master a particular device. It is devoid of a doubt a test to stay educated concerning advancement.

\section{CONCLUSIONS}

Colleges today confront new difficulties. Exponential development in the interest for advanced education, huge declines in government subsidizing for training, the changing nature of information, changing student demographics and desires, what's more, worldwide rivalry [65] in the procurement of advanced education and fast advances in data and correspondences or communication advances request a reconsideration of how colleges satisfy their center elements of capacity or storage, handling or processing, distribution or dissemination, and use of information to real-life issues [66][67]. Before accepting M-learning into the standard direction, attentive examinations must be determined to issues that take place. The general point of view of the present investigation work and endeavors in the M-learning zones recommend that essential contemplations should be paid to the consequences of the various exercises educationally, how they are measured and assessed with a particular finished objective to figure out the soundness of the knowledge grabbed and the slant of the learning gadgets brought into play.

\section{REFERENCES}

[1] Goggin, G. (2006). Cell phone culture: Mobile technology in everyday life. New York: Routledge.

[2] Nyíri, K. (2002). Towards a philosophy of M-Learning.

[3] 'O'Malley et al, (2003). MOBIlearn WP4 - Guidelines for learning/teaching/tutoring in a mobile environment.

[4] Georgiev et al, (2004). M-Learning - a New Stage of ELearning.

[5] Kukulska-Hulme et al, 2005. Mobile learning. A handbook for educators and trainers. Open and flexible learning series, Routledge, London.

[6] Kukulska-Hulme et al,. (2007). An overview of mobile assisted language learning: Can mobile devices support collaborative practice in speaking and listening?

[7] Frohberg, D. (2002). Communities- the MOBIlearn perspective. Retrieved October 10, 2012

[8] Vavoula et al. (2009). Researching mobile learning: frameworks,tools and research designs. Oxford, UK: Peter Lang.
[9] Reynolds et al,. (2010). Web-based museum trails on PDAs for university-level design students: Design and evaluation. Computers \& Education. 55(3), 994-1003.

[10] Chiou et al. (2010). An adaptive navigation support system for conducting context-aware ubiquitous learning in museums. Computers \& Education, 55, 834-845.

[11] Hwang et al (2011). A formative assessment-based mobile learning approach to improving the learning attitudes and achievements of students. Computers \& Education, 56(1), 1023-1031.

[12] Hung et al (2010). Formative assessment design for PDA integrated ecology observation. Educational Technology \& Society, 13(3), 33-42.

[13] Pfeiffera, et al. (2009). Situated learning in the mobile age: mobile devices on a field trip to the sea. ALT-J, Research in Learning Technology, 17(3), 187-199.

[14] Chu et al (2010). A knowledge engineering approach to developing mindtools for context-aware ubiquitous learning. Computers \& Education, 54(1), 289-297.

[15] Coulby et al. (2011). The use of mobile technology for work-based assessment: the student experience. British Journal of Educational Technology. 42(2). 251-265.

[16] Kukulska -Hulme A. (2002): Cognitive, ergonomic and affective aspects of PDA use for learning. Proceedings of the European Workshop on Mobile and Contextual Learning, 32-33, Birmingham, UK, June 2002

[17] Waycott J et al. (2002): Evaluating the use of PDAs as learning and workplace tools: An activity theory perspective.

[18] Keegan, D. (2003). The future of learning: From eLearning to mLearning. Retrieved September 2012.

[19] Economides, A.A., \& Nikolaou, N. (n.d.): Evaluation of handheld devices for mobile learning.

[20] Ahonen et al. (2004). Mobile learning and evaluation. Digital Learning 2 project working papers.

[21] Cavus et al (2009). M-learning: an experiment in using SMS to support learning new English language words. British Journal of Educational Technology, 40(1), 78-91.

[22] Eteokleous et al (2009). Investigating mobile devices integration in higher education in Cyprus: faculty perspectives.

[23] Cohen, A. (2010). Characteristics of effective mobile learning. Retrieved June 2, 2011,

[24] Lan et al (2010). Using RSS to support mobile learning based on media richness theory. Computers \& Education, 55(2), 723-732.

[25] Naismith et al (2006). Reflections on success: A retrospective of the mLearn Conference Series 20022005. Paper presented at the MLearn 2006 Conference, 22-25 October 2006, Banff, Canada.

[26] Luckin et al (2004). SMILE: the creation of space for interaction through blended digital technology. In J. Attewell \& C. Savill-Smith (Eds.). Learning with mobile devices: research and development. London: LSDA, $87-$ 93. 
[27] Attewell et al. (2005). Engaging and Supporting Mobile Learners. Mobile learning anytime everywhere: A book of papers from mLearn 2004, London: LSDA, 15-19.

[28] BenMoussa, C. (2003). Workers on the move: new opportunities through mobile commerce. Proceeding of the International Conference e-Society (IADIS), Lisbon, Portugal, 251-256.

[29] Zhang, D. (2003). Delivery of personalized and adaptive content to mobile devices: a framework and enabling technology. Communications of the Association for Information Systems, 12, 183-202.

[30] Virvou et al (2005). Mobile educational features in authoring tools for personalized tutoring. Computers \& Education, 44, 53-68. Warschauer, M. (2003). Technology and social inclusion: Rethinking the digital divide. Cambridge: MIT Press.

[31] Watts, N. (1997). A Learner-based approach to computer mediated language learning. System, 25(1), 1-8.

[32] Selfe, C. (1999). Technology and literacy in the twentyfirst century: The importance of paying attention. Carbondale, IL: Southern Illinois University Press.

[33] Makoe, M. (2010). Linking mobile learning to the student-centred approach. Retrieved May 12, 2011.

[34] Cavus, N., \& Al-Momani, M.M. (2011). Mobile system for flexible education. Procedia Computer Science. 3 (2011) 1475-1479.

[35] HandLeR project. Retrieved September 2012 from (Interim report). University of Tampere: Hypermedia Laboratory.

[36] Ketamo, H. (2002): mLearning for kindergarten's mathematics teaching, Proceeding of IEEE International Workshop on Wireless and Mobile Technologies in Education (WMTE 2002) , 167-170, Växjö, Sweden, August 2002

[37] Prensky, M. (2007). How to teach with technology: Keeping both teachers and students comfortable in an era of exponential change. Emerging Technologies for Learning

[38] Virvou, et al (2005). Mobile educational features in authoring tools for personalized tutoring. Computers \& Education, 44, 53-68.

[39] Hawisher, G. E., \& Selfe, C. L. (Eds.). (1999). Passions, pedagogies, and 21 st century technologies. Logan: Utah State University Press.

[40] Warschauer, M. (2003). Technology and social inclusion: Rethinking the digital divide. Cambridge: MIT Press.

[41] Phipps et al (2002). Access all areas: Disability, technology and learning. York: JISC.

[42] Uzunboylu et al (2009). Using mobile learning to increase environmental awareness. Computers \& Education, 52(2), 381-389.

[43] Bonk, C. J., \& Graham, C. R. (2006). Handbook of blended learning: global perspectives, local designs. San Francisco, CA: Pfeiffer Publishing.

[44] Ocak, M. (2010). Blend or not to blend: a study investigating faculty members' perceptions of blended teaching. World Journal on Educational Technology, 2(3), 196-205.

[45] Cavus et al (2009). Improving critical thinking skills in mobile learning. Procedia - Social and Behavioral Sciences, 1(1), 434-438.

[46] Sharples et al (2005). Towards a theory of mobile learning. Retrieved June 1, 2011,

[47] Sharples, M. (2003). Disruptive devices: mobile technology for conversational learning. International Journal of Continuing Engineering Education and Lifelong Learning, 12(5/6), 504-520.

[48] Chen et al (2002). A Mobile Scaffolding-Aid-Based Bird - Watching Learning System. Proceedings of IEEE International Workshop on Wireless and Mobile Technologies in Education (WMTE'02), pp.15-22.

[49] Lonsdale et al. (2004). Context awareness for MOBIlearn: creating an engaging learning experience in an art museum. Proceedings of MLEARN 2004 Bracciano, Rome: LSDA.

[50] Smørdal et al, (2005). KNOWMOBILE: mobile opportunities for medical students. In A. KukulskaHulme \& J. Traxler (Eds.),

[51] Muir et al. (2003). The pyramid of usability: A framework for quality course websites. Proceedings of EDEN 12th Annual Conference of the European Distance Education Network, The Quality Dialogue: Integrating Quality Cultures in Flexible, Distance and eLearning, Rhodes, Greece, 15-18 June 2003, 188-194.

[52] Kukulska-Hulme, A. (2005). Mobile usability and user experience. In A. Kukulska Hulme \& J. Traxler (Eds.), Mobile Learning: A handbook for educators and trainers (pp. 45-46). London: Routledge.

[53] Trinder et al. (2005). Expect the unexpected: Practicalities and problems of a PDA project. In A Kukulska-Hulme \& J. Traxler (Eds.). Mobile learning: A handbook for educators and trainers (pp. 92-8). London: Routledge.

[54] Nielsen, J. (2003). Mobile devices: One generation from useful. Retrieved August 2012

[55] Smørdal et al. (2002): PDAs in Medical Education and Practice. Proceeding of IEEE International Workshop on Wireless and Mobile Technologies in Education (WMTE 2002), (p. 140-146), Växjö, Sweden, August 2002

[56] Morg, T. (2012). Batteries on mobile devices drained more quickly by apps which are free, research says. Retrieved on October 10, 2012.

[57] E- and mobile learning system. (n.d.). Retrieved October 10, 2012.

[58] Yeaton, M. (2012). Mobile devices: the new target for data theft. Retrieved October 10, 2012

[59] Mearian, L. (2012). Mobile devices bring cloud storage and security risks to work.

[60] Traxler, J. (2004). Mobile learning - evaluating the effectiveness and the cost. In Jill Attewell and Carol Savill-Smith (eds). MobiLearn: Learning with mobile devices, research and development. LSDA: London 
[61] Gitsaki et al (2013). Researching the UAE iPad Initiative. Plenary presented at the Mobile Learning: Gulf Perspectives Symposium, Abu Dhabi, April 2013.

[62] Kamali, T.A. (2013). Mobile learning from a government perspective. Panel member, UNESCO Second Mobile Learning Week. Paris, 2013.

[63] Ally et al. (2013). Improving communication skills in the workplace using mobile learning. Presentation at the UNESCO Second Mobile Learning Week. February 2013, Paris.
[64] Mims, C. (2011, 1 July). Samsung windfall: all of South Korea's textbooks to go digital by 2015. MIT Technology Review.

[65] L. Rajasingham, 2010, Critical Factors for Successful ELearning: A Case Study of the Universitat Oberta de Catalunya, E-Learn Centre, Internet Interdisciplinary Institute (IN3), Barcelona, Spain..

[66] J. Tiffin et al, 1995, In Search of the Virtual Class: Education in an Information Society, Routledge, New York, NY, USA.

[67] J. Tiffin et al, 2003, The Global Virtual University, Routledge, New York, NY, USA 